\title{
Language Death and Endangered Languages
}

\author{
Baba Zanna Isa, HajjaKaru Ahmed and YaganaGrema \\ Department of Language and Liberal Studies, \\ Ramat Polytechnic P.M.B. 1070 Maiduguri, Nigeria
}

\begin{abstract}
Language is essential in humans' lives; it is what takes to differentiate between animals and humans, it is what we use to understand ourselves. Upon all its status in human life, people are still crying of language disappearance, because many died and some are endangered. There are some questions that supposed to be asked, but only few were raised. We tried to look at major areas such as: the importance of languages, the statistics of languages, what really caused the endangerment, and a way out (solution). Though, the issue is very vast, but we tried and narrowed ourselves down to the minimal level just not to confuse readers.
\end{abstract}

Key words: Language, death, endangered, and revitalization

\section{Introduction}

There are about six to seven thousand languages in the world today but the hurting or terrible thing is at the end of the $21^{\text {st }}$ century almost half of these languages would have perished. According to Crystal $(2000,19)$ it is estimated that in every two weeks or so a language will die off somewhere in this world. Miroslav 2010 quoted Ethnologue $(2005$ 12) there are about 51 languages (now 50) around the world that have only one speaker left: 8 languages (now 7) in the USA, 3 in South America, 3 in Africa, 6 in Asia, 28 in Australia, and 3 in the pacific ocean islands. Nearly or almost 500 languages have less than 100 speakers; 1,500 languages are spoken by less than 1,000 speakers; 3,000 or so languages have up to 10,000 speakers; and 500 languages have no more than 100,000 speakers. It has been calculated that about ninety-six percent $(96 \%)$ of the world's languages are spoken by about or only four percent (4\%) of the globe's population. "Most of us feel we could never become extinct. The Dodo felt that way too." (William Cuppy)

\section{Dead language}

A dead language is a language which is no longer spoken by anyone as their main language, or a language, such as Latin, that is no longer learned as a native language by a speech community. When the last speaker of a language dies, the language too will die. Sometimes it is not necessary to wait for the last speaker to die before considering the language as dead because the last speaker has no one to speak to fluently or frequently. So, the language is extinct, as good as dead.

There are some voices that believed to be the last speakers of their languages. Some years back in Haci Osman in Turkey Linguists went into the village to record TevficEsenç who believed to be the last speaker of Ubykh Language. He couldn't even converse with his own children, because they have become Turkish. What he wanted to be written on his grave, he has already written it on the grave stone in 1984 "This is grave of TevficEsenç. He was the last person able to speak the language they called Ubykh." With the death of Esenç in 1992, Ubykh too joined the ever increasing number of extinct languages.

Let's take for instance, Walsh language which was dead some years back, if not for the sake of revitalization it has become an extinct and followed the other dead languages

In Southern Carolina, four years after, a Native American called Red Thundercloud also died as the last voice of dying tongue (Wappo).

\section{Endangered Languages}

If people find it easier for them to use languages that are easy to conduct business and communicate in them such as English, Dutch, Spanish, Italia etc., then you will find out that the younger ones are not using the local languages, or if the younger ones are not being educated in the languages spoken by a limited number of people (Elizabeth Malone) that means few people are using the languages, then they gradually die. Languages that have fewer or smaller number of speakers are also considered as endangered.

Languages are classified or level according to the following:

1. Languages that safe or viable: these are languages that are supported and used as an official by governments and also have large number of speakers, at least 100,000 speakers or so, then it is considered as safe.

2. Endangered languages: these are kind of languages that learn by children but will cease to be learned in near future by children, if the present condition persists. 
3. Moribund languages: these are terminal decline languages that have ceased to be learned by children but spoken by elders. Therefore, almost doomed or near extinction.

4. Dead/Extinct languages: no longer spoken by any one although they are written materials or recordings.

\subsection{There are factors for the loss of language}

- Language shift - when a language shift towards a stronger language frequently

- Natural disasters such as volcanic eruption, hurricane, tsunami, earthquake, disease

- Human disasters such as invasion, genocide, warfare

- Political reasons such as colonization, education, migration

These factors often result in cultural assimilation or even genocide compare it with/to language, cultural, and educational policies that have taken place in the previous time. Today it is not easy or common to punish people for practicing or using their languages, still languages continue to die.

\subsection{Language preservation}

$50 \%$ of the languages represent vast, largely unmapped terrain on which Philosophers, Linguists, and Cognitive Scientists can chart the full capabilities and limits of the human mind. These languages each of them has a unique local knowledge of natural system and cultures in the region or where it is spoken. To understand human history, you need these languages as a source of evidence. Davis 2003 "TedTalk" said that language is not only exist to express vocabularies and grammatical rules rather it is what made humans who they are.

"Language is not just a body of vocabulary or a set grammatical rule. A language is a flash of human spirit. It is a vehicle through which the soul of each particular culture comes into the material world. Every language is an old-growth forest of the mind, a watershed, a thought, an ecosystem of spiritual possibilities." Wade Davis, Ted Talks 2003

Apart from the uniqueness of the knowledge associated to those languages, the reason(s) for their death was not recorded or documented i.e. both the languages and the knowledge. Heather Lotherington said, the door to all knowledge is language and it is wrong for any language to claim that, only that language is a unique way to acquire knowledge. Some killer languages such English, French among others do feel this idea.

Tsunoda 2012 came up with a suggestion that languages need to be documented because once a language is lost there would be no opportunity to record it. Therefore, it is important to make an adequate documentation of languages while there is an opportunity. Tsunoda said in the process of documenting endangered languages or any language for that matter, there are certain procedures to be followed or should be aim at the following level of quality (Craig 1997: 265; Lehman 1999: 5-6)

" a) accuracy: the documentation must be as reliable as possible, and; b) comprehensiveness: the documentation must be complete as possible. That is, it "should provide a true presentation of the language" (Mithun 2001: 52). In view of these aims, particularly (b), it is vital to take a holistic approach, rather a narrow approach. A holistic approach aims to document a language as a whole, including its socio-cultural background (Tsunoda 1998b)" Tsunoda 2012

Lenore and Whaley reviewed book (endangered language 1998) in which they looked at the present issue in the field of linguistic about minority and disuse languages. Janet was saying that there is always effort to preserve language by individuals or by some cultures when it comes to the issue of language loss, where she related to Nancy Dorian's work on Western Language Ideologies. She stated that one of the factors that contributed for the loss of languages in minority communities is stigmatization. Similarly, bilingualism and nonstandard languages are the underlying factors for low prestige of minority languages. This can only be changed when the social status of the minority language speakers is upgraded, use for religious purposes and rejection of European values. The possible chances of all these are very minimal. Lenore and Whaley also examined the general classification of language maintenance, where they referred to Edwards' model of (1992) for factors of language maintenance, suggested that there is a need for this model to be improved so that it can be applied to or accommodates every community.

Tsunoda (2012) again saying that on one hand languages are disappearing while on the other hand effort were made to preserve those languages that are endangered and even to bring into life the ones that become extinct.

We keep on talking of "language preservation" but the term in linguistic field has or referred to many names. So, Tsunoda (2012)

\subsection{Steps need to be taken to prevent languages from dying}

There are lots of ways need to be followed on how to stop or slowing down language death. The following are some of the steps:

- To stabilizing human population growth 
- To improve the living standard of the rural areas

- To improve the living standard of poor people both in developing and developed countries

- By empowering the local people and not interfering with their way of life and how they govern them selves

- If the political domination by political elites is lifted, the reasons for giving up a language are also weakened

When such steps are taken, the issue of losing languages will be reduce drastically, and a lot of cultures and knowledge would be saved, because we mentioned earlier that every language has a unique system of knowledge and culture.

Lastly, we discovered and noticed that languages are so important and necessary in human life, and we need them in everything we do. There are lots of languages that are extinct and many are endangered. These languages are sick and need to be cured especially in America and Australia. What we have perceived, it is duties of both linguists and governments of various states to deeply involve in rescuing these languages by documenting and recording them as whole, if possible revive some extinct ones. This is not enough, let these languages be taught and used as a medium of instruction in elementary schools and media houses at the local communities where they exist. Language is our identity, let us save it.

\section{References:}

[1]. Danny Hieber (2012) "Why do languages Die?",accessed on $\quad$ www.mises.org/daily/5846/why-do-languages-die\#content

[2]. Elizabeth Malone "Endangered Languages", accessed on www.nsf.gov/news/special reports/linguistics/endangered.jsp

[3]. MiroslavČrný (2010) "Language Death versus Language Survival: A Global Perspective”University of Ostrava Czech Republic, accessed on www.conference.osu.eu/globalization/publ/06-cerny.pdf

[4]. Nettle, D. \& Romaine, S. (2000) "Vanishing Voices: The Extinction of the World"

[5]. RidhaHarwan (2012) "Language shift, Language Death, and Language Loss", accessed on www.ridhaharwan.blogspot.co.uk

[6]. Tsunoda, T. (2012) "Language endangered and Language revitalization" 